\title{
PENGARUH TINGKAT KEPUASAN PEMANFAATAN (UTILITY) POSYANDU TERHADAP STATUS GIZI BALITA (0-5 TAHUN) PADA PUSKESMAS PANDANWANGI KOTA MALANG
}

\author{
Sendhi Tristanti , Nurnaningsih Herya Ulfah ${ }^{1}$, Tisnalia Merdya Andiastanti ${ }^{1}$ \\ * Dosen Program Studi Ilmu Kesehatan Masyarakat Jurusan Ilmu Kesehatan Fakultas Ilmu Keolahragaan \\ Universitas Negeri Malang \\ emaildr.sendhi@gmail.com
}

\begin{abstract}
ABSTRAK
Masalah gizi di Indonesia tidak dapat kita abaikan karena dapat menimbulkan dampak yang negatif. Kekurangan gizi berdampak terhadap pertumbuhan, perkembangan intelektual dan produktivitas.Posyandu sebagai salah satu pelayanan kesehatan di desa untuk memudahkan masyarakat memantau keadaan gizi anak balitanya dapat membantu pencegahan secara dini masalah gizi. Tujuan penelitian ini adalah Mengetahui Pengaruh Utility Posyandu terhadap status gizi Balita (0-5 tahun) di Wilayah Puskesmas Pandanwangi Kota Malang. Metode penelitian ini adalah analitik dengan rancang bangun crosssectional. Adapun populasi dalam penelitian ini adalah balita usia (0-5 tahun) di Posyandu wilayah Puskesmas Kota Malang. Dengan jumlah sampel adalah 105 responden yaitu Ibu yang memiliki balita berusia 0-5 tahun. Analisis data penelitian ini menggunakan uji somers'd Untuk mengetahui pengaruh utility posyandu terhadap kesehatan balita (0-5 tahun). Hasil penelitian ini adalah Berdasarkan pengukuran status gizi balita (0-5 tahun) di Wilayah Puskesmas Pandanwangi Kota Malang maka dapat diperoleh hasil bahwa sebesar 78,9\% balita berada pada status gizi normal. Diketahui bahwa sebesar $51,4 \%$ responden merasa puas terhadap pelayanan di Posyandu. Kesimpulan dari penelitian ini adalah tidak ada hubungan antara Pemanfaatan (Utility) Posyandu Terhadap Status Gizi Balita (0-5 Tahun) Pada Puskesmas Pandanwangi Kota Malang.
\end{abstract}

Kata kunci : utility, status gizi, posyandu

Nutritional problems in indonesia could not we take for granted because it could create negatif side. A nutritional deficiency had an impact on the growth of children, the intellectual development and productivity. Posyandu as one of health services in villages is a facilitate the public to monitors the state of child nutrition. It can help prevention in a premature manner program of the nutrition problem.The purpose of this research is to know the influence of utility posyandu against the nutritional status of under-fives ( year 5-0 in the area puskesmas pandanwangi poor city. A method of this research is analytic with crosssectional design. The population in this study are toddlers age (5-0 years) of posyandu areas. Total sample is 109 respondents. The respondent is mother who have toddlers aged 5-0 years. Data analysis this research using test somer's to know the influence of utility posyandu on health toddlers $(0-5$ years). The result of this research is based on the measurement of nutritional status of toddlers (0-5 years). We known that $78.9 \%$ toddlers be normal nutrition status. Its also seen that of $51,4 \%$ of respondents satisfied with service in posyandu.The conclusion of this research is there was no connection between the use of (utility) posyandu about the status of nutrition toddlers ( thrashed 5-0 years) for puskesmas pandanwangi Malang city

Key words: Utility, Nutrition status, Posyandu 


\section{PENDAHULUAN}

Angka kematian balita di negara-negara berkembang khususnya Indonesia masih cukup tinggi. Badan kesehatan dunia (WHO) memperkirakan bahwa 54\% kematian anak disebabkan oleh keadaan gizi yang buruk.

Sementara masalah gizi di Indonesia mengakibatkan lebih dari 80 persen kematian anak (WHO, 2011). Prevalensi balita gizi buruk merupakan salah satu indikator Millenium Development Goals (MDGs) yang harus dicapai disuatu daerah (kabupaten/kota) pada Tahun 2015, yaitu terjadinya penurunan prevalensi balita gizi buruk menjadi $<3,6 \%$. Sebanyak 4 juta anak Indonesia yang menderita gizi kurang terancam jatuh ke derajat gizi buruk, jika tidak mendapat penanganan semestinya. Masalahnya, dari 700.000 penderita gizi buruk, kemampuan pemerintah menangani hanya 39.000 anak gizi buruk atau sekitar $5,57 \%$ per tahun.

Kondisi ini menjadi ancaman karena dari 250.000 Posyandu yang ada, tidak lebih dari $50 \%$ yang masih aktif. Berarti cakupan pengendalian kualitas gizi balita di Indonesia tidak lebih dari 50\%.Dampaknya, probabilitas terjadinya gizi buruk sangat tinggi (Khomsan,Ali, 2008). Oleh karena itu pemanfaatan posyandu dapat dijadikan sebagai alternatif solusi untuk mengatasi angka gizi buruk agar tidak semakin meningkat.

Berdasarkan Laporan Riset Kesehatan Dasar Provinsi Jawa Timur dalam kategori Berat badan/ Umur $(\mathrm{BB} / \mathrm{U})$ didapat balita dengan status gizi buruk sekitar $4,8 \%$, balita dengan status gizi kurang sekitar $12,6 \%$, balita dengan status gizi baik sekitar 78,0 \%, balita yang terkena gizi lebih sekitar 4,5 $\%$ dari 29.952 penduduk (Riskesdas, 2007).

Salah satu upaya untuk mengurangi angka kesakitan dan kematian anak balita adalah dengan melakukan pemeliharaan kesehatan. Pemeliharaan kesehatan anak balita

dititikberatkan kepada upaya pencegahan dan peningkatan kesehatan serta pengobatan dan rehabilitasi yang dapat dilakukan di puskesmas, puskesmas pembantu, polindes, dan terutama di posyandu, Posyandu sebagai lini pertama pusat pemberdayaan masyarakat merupakan tempat yang paling cocok untuk memberikan pelayanan kesehatan pada balita secara menyeluruh dan terpadu (Widiastuti\&Kristiani, 2006).

Manfaat yang diperoleh dengan membawa balita ke posyandu adalah: 1) anak mendapatkan kesehatan ke arah yang lebih baik, 2) mendapatkan

kemudahan pelayanan di satu kesempatan dalam satu tempat, 3), dapat menghindari pemborosan waktu. Dengan tingkat partisipasi masyarakat yang mencapai target yang diharapkan dan cakupan pelayanan dapat diperluas dapat mempercepat terwujudnya peningkatan derajat kesehatan balita (Widiastuti\&Kristiani, 2006).

Sejalan dengan program yang dilaksanakan oleh MDGs tentang menurunkan angka kematian balita terdapat pula program Pemerintah Indonesia tentang revitalisasi posyandu. Revitalisasi posyandu adalah upaya

pemberdayaan posyandu untuk mengurangi dampak dari krisis ekonomi terhadap penurunan status gizi dan kesehatan ibu dan anak. Maka diperlukan juga keaktifan dari ibu untuk memeriksakan anaknya di posyandu demi meningkatnya status gizi anak tersebut (Widiastuti\&Kristiani, 2006).

Dinas Kesehatan Kota Malang memiliki 15 UPT Puskesmas, berdasarkan Profil Dinas Kesehatan sepanjang Tahun 2014 untuk 15 Puskesmas tersebut diperoleh data balita dengan status gizi normal adalah sebagai berikut Arjuno (92,68\%), Bareng (90,25\%), Rampalcelaket $(89,14 \%)$,

Cisadea (90,30\%), Kendalkerep 
(92,33\%), Pandanwangi (91,37\%), Kedungkandang (91,49\%), Gribig (91,56\%), Arjowinangun (92,95\%), Janti (93,31\%), Ciptomulyo (91,94\%), Mulyuroje $(91,92 \%)$, Dinoyo $(92,69 \%)$,

Mojolangu $\quad(94,31 \%), \quad$ Kendalsari $(88,79 \%)$ (Dinkes Kota Malang, 2014). Berdasarkan data tersebut, maka peneliti memilih Puskesmas Pandanwangi sebagai tempat penelitian dikarenakan data balita dengan status gizi normal pada Tahun 2014 pada Puskesmas Pandanwangi masih dibawah Puskesmas Kendalkerep.

Berdasarkan latar belakang
tersebut maka,peneliti tertarik
mengadakan penelitian untuk
mengetahui Pengaruh Tingkat Kepuasan
Pemanfaatan (utility) Posyandu
Terhadap Gizi Balita (0-5tahun) Pada
Puskesmas Pandanwangi Kota Malang.

\section{METODE}

Penelitian ini merupakan penelitian analitik dengan pendekatan cross sectional yaitu suatu penelitian yang mempelajari pengaruh antara independen dan dependen, dimana observasi dan pengukuran variabel sekali dan sekaligus pada waktu yang sama (Riyanto, 2012). Dalam penelitian ini yang akan dipelajari adalah pengaruh tingkat kepuasan (Utility) posyandu terhadap status gizi balita (0-5 tahun). Populasi dalam penelitian ini adalah seluruh ibu balita berusia 0-5 tahun di Wilayah Puskesmas Pandanwangi Kota Malang Kota Malang yang memiliki buku KIA sebanyak 4620. Besar sampel dalam penelitian ini menggunakan software sample size dengan cara memasukkan jumlah populasi dan probabilitas kejadian $(0,05)$ dan besaran derajat ketepatan 90\%. Dan diketahui bahwa sampel responden dalam penelitian ini sebanyak 109 orang.

Instrumen yang dipergunakan dalam penelitian ini adalah Pengukuran kesehatan, kuisioner dan lembar observasi. Pengukuran kesehatan balita 05 tahun melalui pengukuran Berat Badan (BB) dan Tinggi Badan (TB) akan disesuaikan pengklasifikasian WHO. Untuk penyebaran kuisioner, dilakukan untuk mengetahui tingkat kepuasan pemanfaatan (utility) posyandu di wilayah Puskesmas Pandanwangi Kota Malang. Dan untuk observasi

dilakukan dengan melihat Kartu Menuju Sehat (KMS) Balita 0-5 tahun pada posyandu di wilayah Puskesmas Pandanwangi Kota Malang.

Untuk mengetahui gambaran status gizi balita dilakukan pengukuran BB Ideal dengan rumus: BB/TB. Pedoman pengukuran status gizi balita yang

digunakan adalah KMK no. 1995/menkes/SK/XII/2010 tentang pedoman standar antropometri penilaian status gizi.,Yaitu :
a. Sangat Kurus $=<-3 \mathrm{SD}$
b. Kurus $=-3 \mathrm{SD}-<-2 \mathrm{SD}$
c. Normal $=-2 \mathrm{SD}-2 \mathrm{SD}$
d. Gemuk $=>2 \mathrm{SD}$

Kemudian, untuk mengetahui gambaran tingkat kepuasan terhadap penggunaan posyandu yang diukur melalui dimensi kualitas pelayanan diperoleh dari hasil kuisioner. Data yang diperoleh dari hasil checklist diolah secara manual dengan proses: editing, coding, scoring dan tabulating. Total skor dalam kuisioner akan dikelompokkan menjadi 3 yaitu:
a. Kurang Puas $=34-67$
b. Puas $=68-101$
c. Sangat Puas $=102-132$

Hasil penelitian diuji menggunakan Somers'd dengan keputusan pengujian hipotesis penelitian didasarkan pada taraf signifikan 0,05. Uji dilakukan dengan taraf signifikan 0,05 yang berarti jika $<\alpha(0,05)$ maka $\mathrm{H}_{0}$ diterima, dan berarti ada pengaruh tingkat kepuasan penggunaan (utility) Posyandu terhadap status gizi balita (0-5 Tahun) di Puskesmas Pandanwangi Kota Malang 
Tahun 2015. Akan tetapi, apabila $>\alpha$ $(0,05)$, maka $\mathrm{H}_{0}$ ditolak, yang artinya tidak ada pengaruh tingkat kepuasan pemanfaatan (utility) Posyandu terhadap status gizi balita (0-5 Tahun) di Puskesmas Pandanwangi Kota Malang Tahun 2015. Untuk memudahkan penarikan kesimpulan maka digunakan perangkat software komputer.

HASIL

Gambaran Status Gizi Balita (0-5 tahun) di Wilayah Puskesmas Pandanwangi Kota Malang Melalui Pengukuran BB Ideal dapat dilihat pada Tabel 1 berikut.

Tabel 1. Hasil status gizi balita (0-5 Tahun) di Puskesmas Pandanwangi Kota Malang Tahun 2015

\begin{tabular}{llcc}
\hline \multirow{2}{*}{ NO } & Status Gizi & Jumlah & Presentase (\%) \\
\hline 1 & Sangat kurus & 5 & 4,5 \\
\hline 2 & Kurus & 9 & 8,3 \\
\hline 3 & Normal & 86 & 78,9 \\
\hline 4 & Gemuk & 9 & 8,3 \\
\hline Total & & $\mathbf{1 0 9}$ & $\mathbf{1 0 0}$ \\
\hline
\end{tabular}

Sumber : Data Primer 2015

Hasil penelitian berdasarkan pada Tabel 1. Gambaran Status Gizi Balita (0-5 tahun) menunjukkan sebesar $78,9 \%$ responden berstatus gizi normal. Tingkat Kepuasan terhadap pemanfaatan (Utility) posyandu dalam penelitian ini diukur melalui dimensi kualitas pelayanan: (1) Tangibility, (2) Reliability, (3) Responsiveness, (4) Assurance dan (5) Empaty. Untuk Tangibility diketahui bahwa sebesar $100 \%$ responden di Puskesmas Pandanwangi Malang menyatakan Posyandu memiliki alat timbang berat badan dan memiliki alat pengukur panjang/tinggi badan bayi. Namun ada pernyataan yang memiliki respon berbeda yaitu sebesar $34 \%$ responden menyatakan bidan datang terlambat dan 97,2\% responden menyatakan kader Posyandu datang terlambat. Adanya keterlambatan ini menyebabkan antrian dari ibu balita semakin banyak sehingga pelayanan semakin lama diterima oleh ibu balita.

Hasil Reliability dalam penelitian adalah sebesar 99,1\% responden di Puskesmas Pandanwangi Malang menyatakan kader/petugas Posyandu bertindak cepat dalam memberikan pelayanan. Dan sebesar $99,1 \%$ responden menyatakan kader/petugas Posyandu menjelaskan dengan jelas prosedur pemberian obat saat anak sakit. Untuk komponen Responsiveness adalah sebesar 100\% responden menyatakan bidan bersikap ramah dan sopan dan sebesar 99,1\% responden menyatakan kader Posyandu bersikap ramah dan sopan. Namun sebesar $18,4 \%$ responden menyatakan bidan melakukan pemeriksaaan dengan perlakuan kasar

Hasil Assurance dalam penelitian ini adalah sebesar $99,1 \%$ responden di Puskesmas Pandanwangi Malang menyatakan bidan memberikan kenyamanan pada ibu untuk bertanya dan mendapatkan pelayanan. Dan sebesar $100 \%$ responden menyatakan bidan/kader selalu melakukan pencatatan dan pengukuran pada bayi. Namun diketahui juga bahwa sebesar $26,6 \%$ reponden menyatakan jumlah bidan kurang untuk melakukan pelayanan. Untuk komponen Empaty dalam penelitian ini menunjukkan bahwa sebesar $93,6 \%$ responden di

Puskesmas Pandanwangi Malang menyatakan Bidan/Kader Posyandu membantu mengurangi rasa cemas saat 
bayi ketakutan mengikuti kegiatan posyandu. Dan sebesar $92,7 \%$ responden menyatakan bidan memberikan penjelasan pada saat melakukan pemeriksaan.
Berdasarkan kelima komponen tersebut maka tingkat kepuasan penggunaan (utility) posyandu tahun 2015 Puskesmas Pandanwangi Kota Malang dapat dilihat pada Tabel 2.

Tabel 2. Distribusi Responden di Puskesmas Pandanwangi Kota Malang Berdasarkan Tingkat Kepuasan Penggunaan (Utility) Posyandu tahun 2015

NO Tingkat Kepuasan Penggunaan Jumlah $\quad$ Presentase (\%) (utility) Posyandu

\begin{tabular}{clcc}
\hline 1 & Puas & 56 & 51,4 \\
\hline 2 & Sangat puas & 53 & 48,6 \\
\hline & Total & $\mathbf{1 0 9}$ & $\mathbf{1 0 0}$
\end{tabular}

Sumber : Data Primer 2015

Hasil penelitian berdasarkan tingkat kepuasan pemanfaatan (utility) posyandu di Puskesmas Pandanwangi Kota

Malang menunjukkan dari 109 responden sebagian besar merasa puas, yaitu sebesar $51,4 \%$ responden.

Hasil uji Somers'd Pengaruh tingkat kepuasan penggunaan (utility) posyandu terhadap status gizi balita (1-5 Tahun) di Puskesmas Pandanwangi Kota Malang Tahun 2015 diketahui bahwa Symetric (Kedua variabel setara/tidak ada arah) dengan ditunjukkan besar nilai korelasi sebesar 0,050 (Sangat lemah). Angka signifikansi 0,584 atau diatas 0,05 (5\%), yang berarti kedua variabel tidak berhubungan secara nyata. Dengan demikian $\mathrm{H}_{0}$ diterima dan $\mathrm{H}_{1}$ ditolak, yang artinya tidak ada pengaruh secara

nyata antara tingkat kepuasan pemanfaatan (utility) posyandu terhadap status gizi balita (1-5 tahun) di Puskesmas Pandanwangi Kota Malang Tahun 2015.

\section{PEMBAHASAN}

Gambaran Status Gizi Balita (0-5 Tahun) Di Wilayah Puskesmas Pandanwangi Kota Malang Melalui Pengukuran BB Ideal

Berdasarkan pengukuran status gizi balita (0-5 tahun) di Wilayah Puskesmas Pandanwangi Kota Malang dan pengkategorian berdasarkan KMK no. 1995/menkes/SK/XII/2010 tentang pedoman standar antropometri penilaian status gizi maka dapat diperoleh hasil bahwa sebesar $78,9 \%$ balita berada pada status gizi normal. Hal ini menunjukkan bahwa balita di Puskesmas Pandanwangi Kota Malang dalam keadaan sehat.

Faktor yang mempengaruhi keadaan status gizi balita adalah pendapatan keluarga, pengetahuan ibu, pendidikan ibu, pekerjaan ibu dan konsumsi makanan (Suhardjo, 2003) sedangkan menurut Soekirman (2000) Faktor yang mempengaruhi status gizi balita adalah

1) Penyebab langsung yaitu makanan anak dan penyakit infeksi yang mungkin diderita anak. Timbulnya gizi kurang tidak hanya karena makanan yang kurang, tetapi juga

karena penyakit. Anak yang mendapatkan makanan cukup baik, tetapi sering diserang diare atau demam, akhirnya dapat menderita kurang gizi. Demikian juga pada anak yang makan tidak cukup baik, maka daya tahan tubuhnya akan melemah. Dalam keadaan demikian mudah diseranginfeksiyangdapat mengurangi nafsu makan, dan akhirnya dapat menderita kurang gizi.

Pada kenyataannya keduanya baik makanan dan penyakit infeksi secara bersama-sama merupakan penyebab 
kurang gizi. 2) Penyebab tidak langsung yaitu ketahanan pangan di

keluarga, pola pengasuhan anak, serta pelayanan kesehatan dan kesehatan lingkungan.

\section{Gambaran Tingkat Kepuasan Penggunaan (Utility) Posyandu Di Wilayah Puskesmas Puskesmas Pandanwangi Kota Malang}

Berdasarkan penelitian yang sudah dilakukan dapat diketahui bahwa sebesar $51,4 \%$ responden merasa puas terhadap pelayanan di Posyandu.

Menurut Lupiyoadi (2006) mengemukakan bahwa pasien dalam mengevaluasi kepuasan terhadap jasa pelayanan yang diterima mengacu pada beberapa aspek yaitu:a) Kualitas Produk atau Jasa; b) Kualitas pelayanan; c) Faktor emosional; d) Harga; e) Biaya.

Tingkat kepuasan responden terhadap pelayanan posyandu dalam penelitian ini dapat dilihat dari (1) Tangibility, (2) Reliability, (3) Responsiveness, (4) Assurance dan (5) Empaty. Secara keseluruhan dari hasil menunjukkan kepuasan pada pelayanan posyandu yang diberikan. Namun ada beberapa pertanyaan yang masih dalam kategori ketidakpuasan yaitu pada komponen tangibility sebesar $34 \%$ responden menyatakan bidan datang terlambat dan 97,2\% responden menyatakan kader Posyandu datang terlambat. Pada komponen Responsiveness, diketahui bahwa sebesar $18,4 \%$ responden

menyatakan bidan melakukan pemeriksaaan dengan perlakuan kasar. Dan pada komponen Assurance diketahui sebesar $26,6 \%$ reponden menyatakan jumlah bidan kurang untuk melakukan pelayanan. Beberapa item yang menunjukkan ketidakpuasan tersebut harus segera diselesaikan sehingga tidak akan mempengaruhi kualitas dari posyandu. Menurut Tjiptono (2008) dampak ketidakpuasan pasien terhadap pelayanan menyebabkan pasien akan beralih ke pemberi pelayanan lainnya dan dari mereka tidak akan pernah kembali lagi. pelanggan yang tidak puas rata-rata menyampaikan masalah keluhan tersebut kepada orang lain, sehingga mampu mempengaruhi persepsi orang lain untuk menggunakan pelayanan tersebut. Selain itu, pelanggan yang tidak puas ingin mendapatkan keadilan dan ingin mendapatkan ganti rugi.

\section{Pengaruh Tingkat Kepuasan Pemanfaatan (Utility) Posyandu Terhadap Status Gizi Balita (1-5 Tahun) Di Wilayah Puskesmas Pandanwangi Kota Malang}

Berdasarkan hasil penelitian diketahui bahwa Somer's menunjukkan angka korelasi yang lemah karena jauh di bawah 1 dan memiliki nilai probabilitas jauh diatas 0,05. Maka dapat disimpulkan bahwa tidak ada pengaruh dari kedua variabel. Hal ini menunjukkan bahwa status gizi Diwilayah Puskesmas Pandanwangi Kota Malang tidak dipengaruhi oleh tingkat kepuasan pemanfaatan (utility) posyandu. Kepuasan pelanggan merupakan konstruk yang berdiri sendiri dan dipengaruhi oleh kualitas layanan (Oliver, 1980). Kualitas layanan juga dapat mempengaruhi loyalitas pelanggan secara langsung (Zeithaml dkk., 1996) sehingga apabila diketahui bahwa tingkat kepuasan pemanfaatan (utility) tidak memiliki hubungan dengan status gizi, dapat ditarik kesimpulan bahwa ada faktor lain yang dapat mempengaruhi status gizi selain kepuasan pemanfaatan.

Keterbatasan dalam penelitian ini adalah tidak mempertimbangkan kondisi balita pada saat penelitian. Sehingga status gizi yang diukur hanyalah pada saat penelitian. 


\section{KESIMPULAN}

Berdasarkan pengukuran status gizi balita (0-5 tahun) di Wilayah Puskesmas Pandanwangi Kota Malang maka dapat diperoleh hasil bahwa sebesar 78,9\% balita berada pada status gizi normal. Hal ini menunjukkan bahwa balita di Puskesmas Pandanwangi Kota Malang dalam keadaan sehat. Berdasarkan penelitian yang sudah dilakukan dapat diketahui bahwa sebesar $51,4 \%$ responden merasa puas terhadap pelayanan di Posyandu. Berdasarkan olah data yang dilakukan didapat hasil berupa tidak adanya pengaruh antara status gizi di wilayah Puskesmas Pandanwangi Kota Malang dengan tingkat kepuasan pemanfaatan (utility) posyandu.

\section{SARAN}

Perlu dilakukan penelitian lebih lanjut mengenai faktor yang mempengaruhi status gizi pada balita selain variabel yang digunakan dalam penelitian.

\section{DAFTAR PUSTAKA}

Dinkes Kota Malang, 2014. Profil Kesehatan Dinas Kota Malang. Malang

$\begin{array}{cr}\text { Keputusan Menteri } & \text { Kesehatan } \\ \text { Republik } & \text { Indonesia } \\ \text { Nomor:1995/Menkes/SK/XI } \\ \text { I/2010 tentang Standar } \\ \text { Antropometri penilaian } \\ \text { status gizi anak. }\end{array}$

Lupiyoadi, Hamdani. 2006. Manajemen Pemasaran Jasa, Edisi Kedua. Jakarta: Penerbit Salemba Empat.

Oliver, R,L. 1980. A cognitive Model Of The Atecedents And Consequences Of Satisfaction Decisions. Journal of Marketing Research. Vol. XVII (November), pp. 460-469

Suhardjo. 2003. Berbagai Cara Pendidikan Gizi. Jakarta: Bumi Aksara

Soekirman, 2000. Ilmu Gizi dan Aplikasinya untuk Keluarga dan Masyarakat. Jenderal Pendidikan Tinggi, Jakarta :8485.

Tjiptono, Fandy. 2008. Strategi Pemasaran. Yogjakarta: Penerbit Andi

Widiastuti, I., A dan Kristiani. 2006. Pemanfaatan Posyandu di Kota Denpasar. Yogyakarta : Program Magister Kebijakan dan Manajemen

Pelayanan Kesehatan, Universitas Gadjah Mada

World Health Organization, 2011. Childhood Overweight and Obesity. Available from: http://www.who.int/dietphysica lactivity/childhood/en.html

Zeithaml, VA., Bitner MJ, 1996. Delivering and Performing Service. Part Five. Services Marketing. International Ed., The Mc Graw Hill Companies, Inc. 